\title{
Izquierdo Lehmann
}

Luis Izquierdo Arquitecto, Pontificia Universidad Católica de Chile

Antonia Lehmann Arquitecta, Pontificia Universidad Católica de Chile 


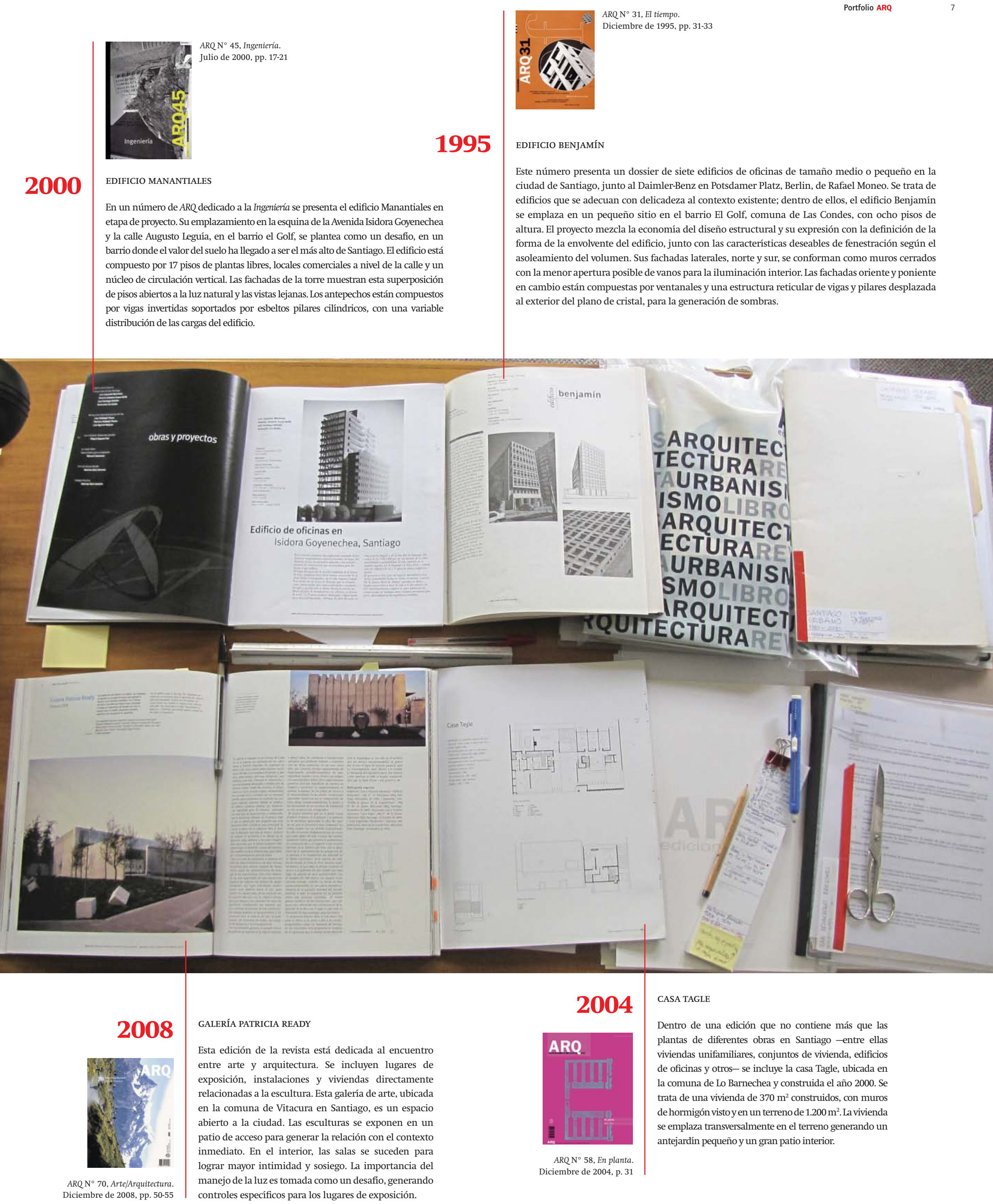




\section{EDIFICIO CRUZ DEL SUR}

fotografía- Cristóbal Palma, Luis Izquierdo

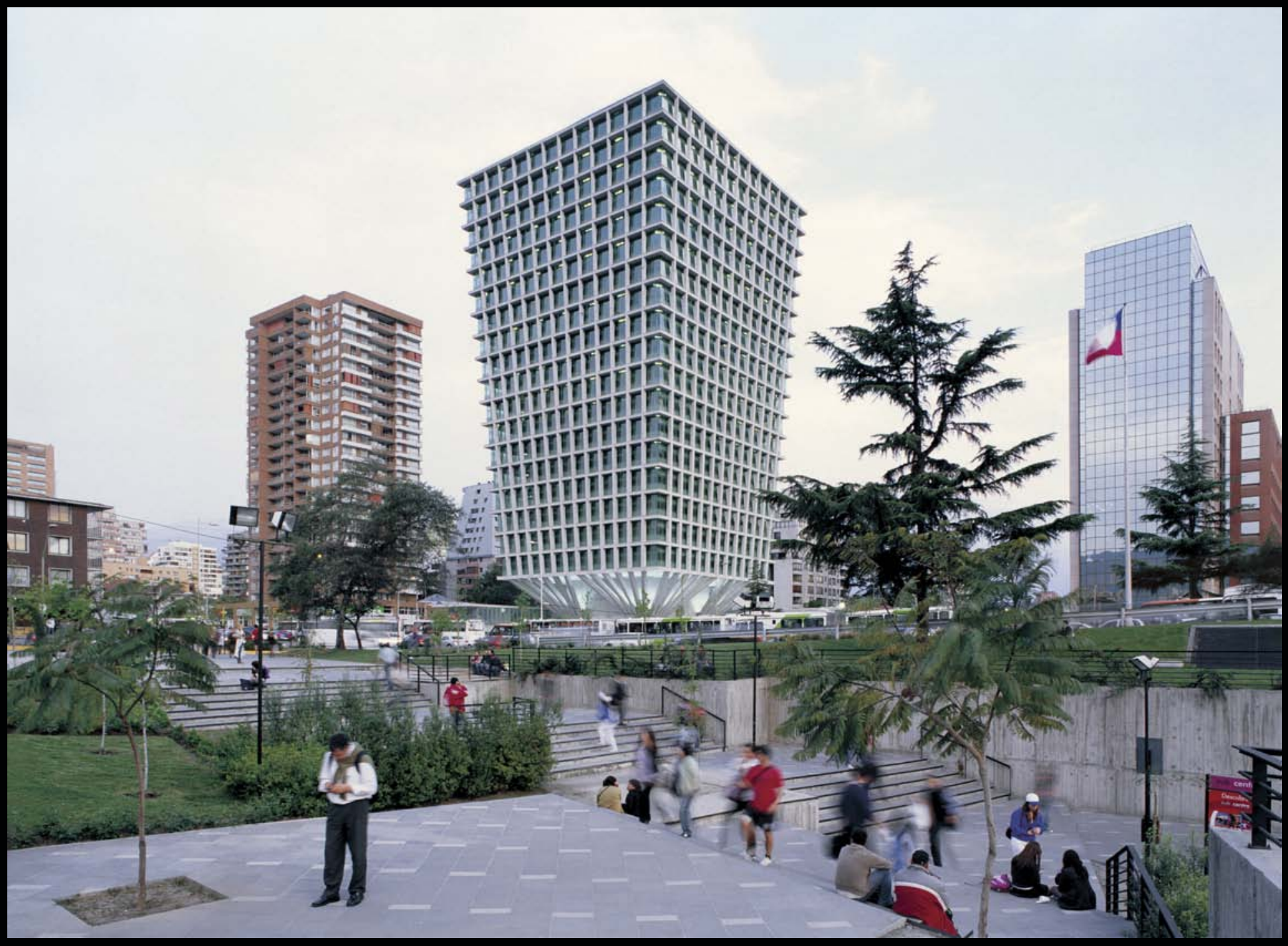

El proyecto consiste en una torre de oficinas con placa comercial ubicada en el cruce de Avda. Apoquindo, eje principal de Santiago, y Avda. Américo Vespucio, anillo de circunvalación de la ciudad. A pesar de su importancia urbana, el lugar está mal conformado por un cruce vial en desnivel y por distintos edificios de diversa altura y calidad, varios de ellos resultantes de una funesta norma de rasantes antigua, apodados lustrines. El terreno está inmediato a un acceso a la estación de metro Escuela Militar, que concentra el mayor flujo diario de toda la red. El predio es resultante de la fusión de cinco lotes cuya gestión de compra realizamos nosotros mismos. Es, en su parte mayor, de planta aproximadamente cuadrada, abierto a la calle en tres de sus frentes: a Avda. Apoquindo al norte, a calle Cruz del Sur al poniente y a calle Félix de Amesti al oriente. Dada su ubicación, la torre enfrenta el eje de Avda. Apoquindo, desde un par de kilómetros de distancia, como remate visual del subcentro de oficinas a lo largo de dicha avenida. 


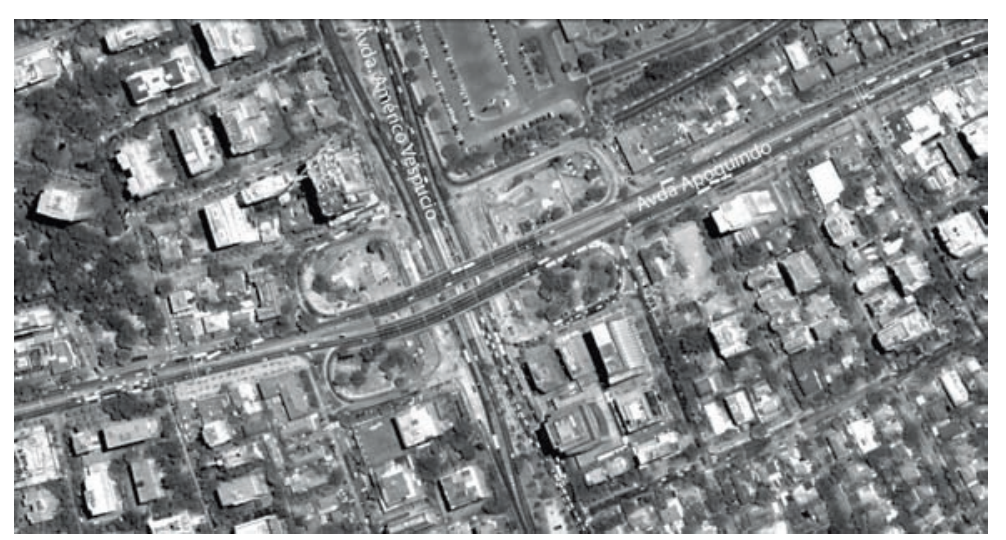

Cruce Avenidas Amércio Vespucio y Apoquindo. Fuente: Servicio de imágenes del planeta Google Earth ${ }^{T M}$
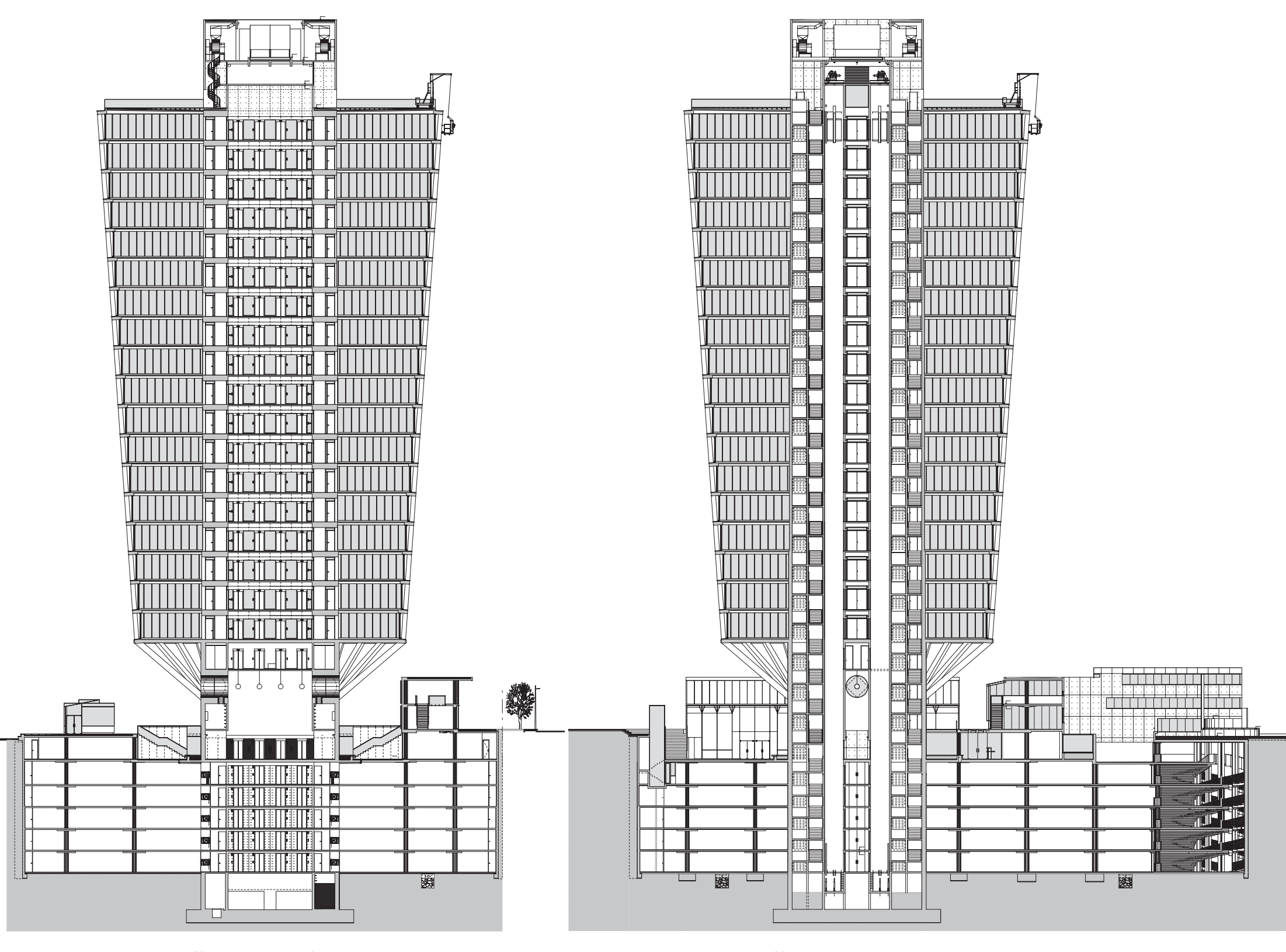

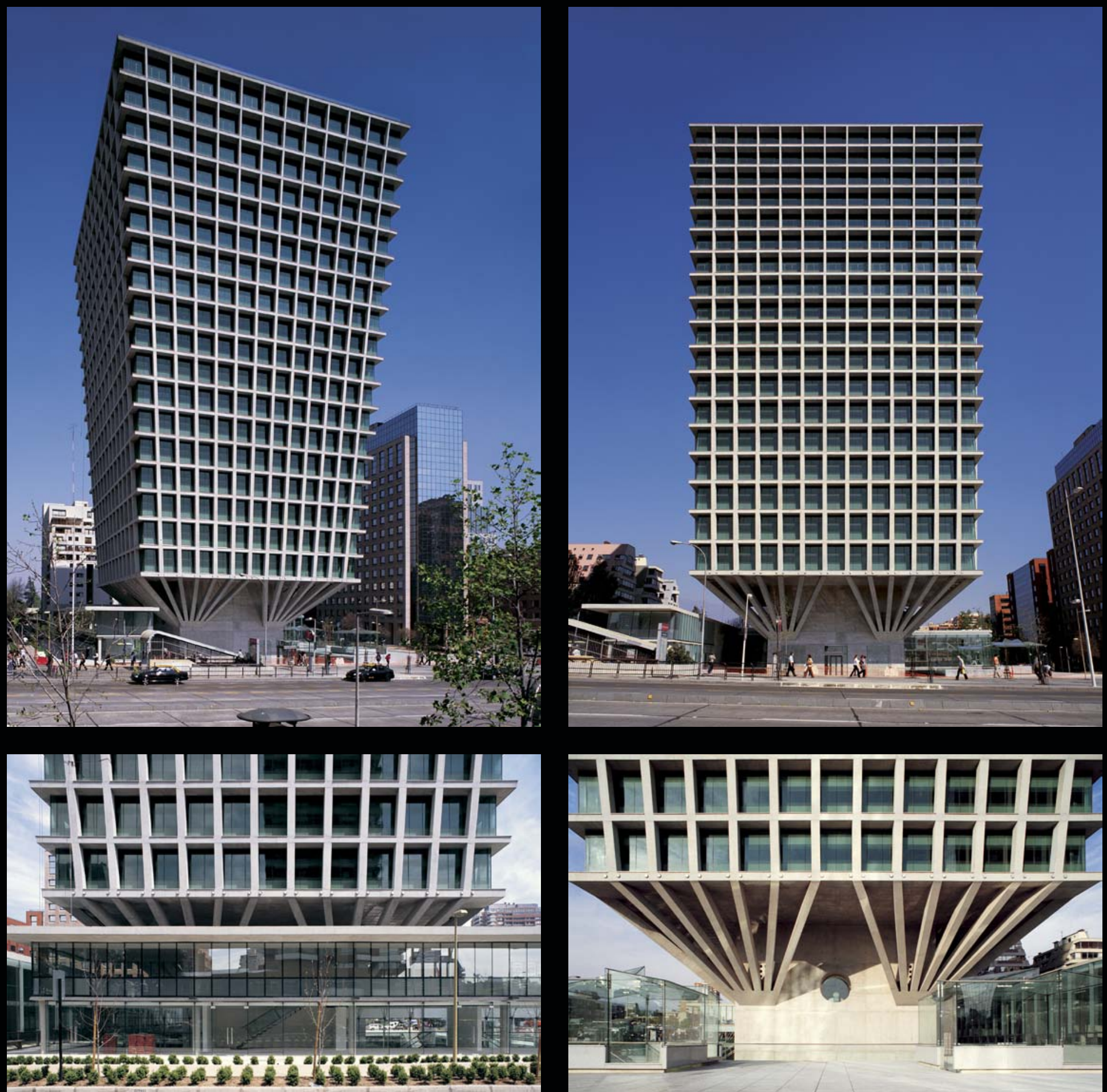

La normativa aplicable permitúa la construcción de una torre de un máximo de 21 pisos, con una superficie edificable de $18.738 \mathrm{~m}^{2}$-que era necesario copar, considerando la incidencia del valor del suelo en el costo de lo vendible-, con plantas de forma cuadrada de aproximadamente $1.000 \mathrm{~m}^{2}$ de superficie promedio cada una y con un núcleo de circulaciones verticales conteniendo una batería de ocho ascensores más dos cajas de escaleras dobles y servicios, ocupando un área de aproximadamente 15 x 15 m. Además la norma requería una placa comercial de dos pisos de alto, con

edificación continua levantada en la línea de edificación frente a las tres calles en el perímetro del terreno, cuya cabida edificable, descontados los accesos a la torre y a los estacionamientos, era de aproximadamente $4.000 \mathrm{~m}^{2}$. Por último, exigía también una dotación de casi 600 estacionamientos, equivalentes a una superficie total de 18.000 $\mathrm{m}^{2}$, la cual, dividida por el área disponible de terreno, da cinco pisos subterráneos. Como se ve, la volumetría del edificio queda bastante acotada por la aplicación de la norma. 

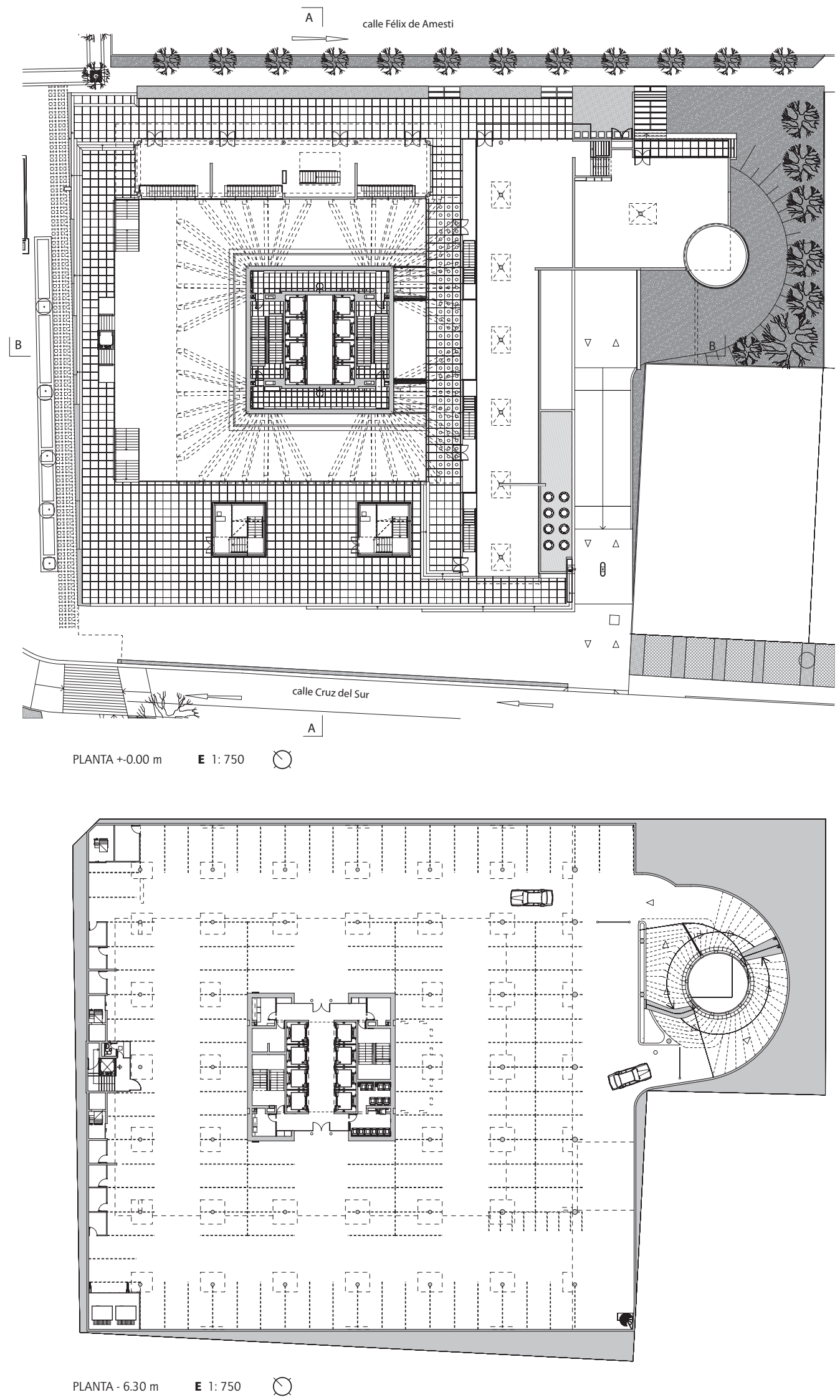

Dada la alta densidad peatonal y la pobreza de espacio público en el sector, nuestra primera decisión de proyecto fue despejar todo lo posible el nivel de suelo para liberar el interior del terreno como extensión del espacio público. Esto era factible soterrando gran parte de la superficie comercial del programa y retirando el resto de la placa a los bordes de fondo del terreno, para conformar una esquina de plaza interior accesible en tres de sus frentes. Además, vimos que era posible estructurar la torre de modo que cayera al suelo solamente el fuste con las circulaciones verticales, considerando la proporción de la altura y la base del volumen edificable y el hecho de que estuviera centrado en plantas cuadradas, lo que evitaba torsiones producidas por fuerzas sísmicas en la estructura. Un primer análisis estructural ratificó la posibilidad de un diseño donde el fuste tomara por sí solo el corte basal y el momento volcante de la masa estimada del volumen. Por otra parte, al caer en los subterráneos sólo con este fuste de circulaciones indispensable, se prescinde de otras columnas que comprometan una distribución de los estacionamientos estrictamente ajustada a sus modulaciones. Así se logra en estas plantas un rendimiento óptimo, de $27 \mathrm{~m}^{2}$ por estacionamiento. 

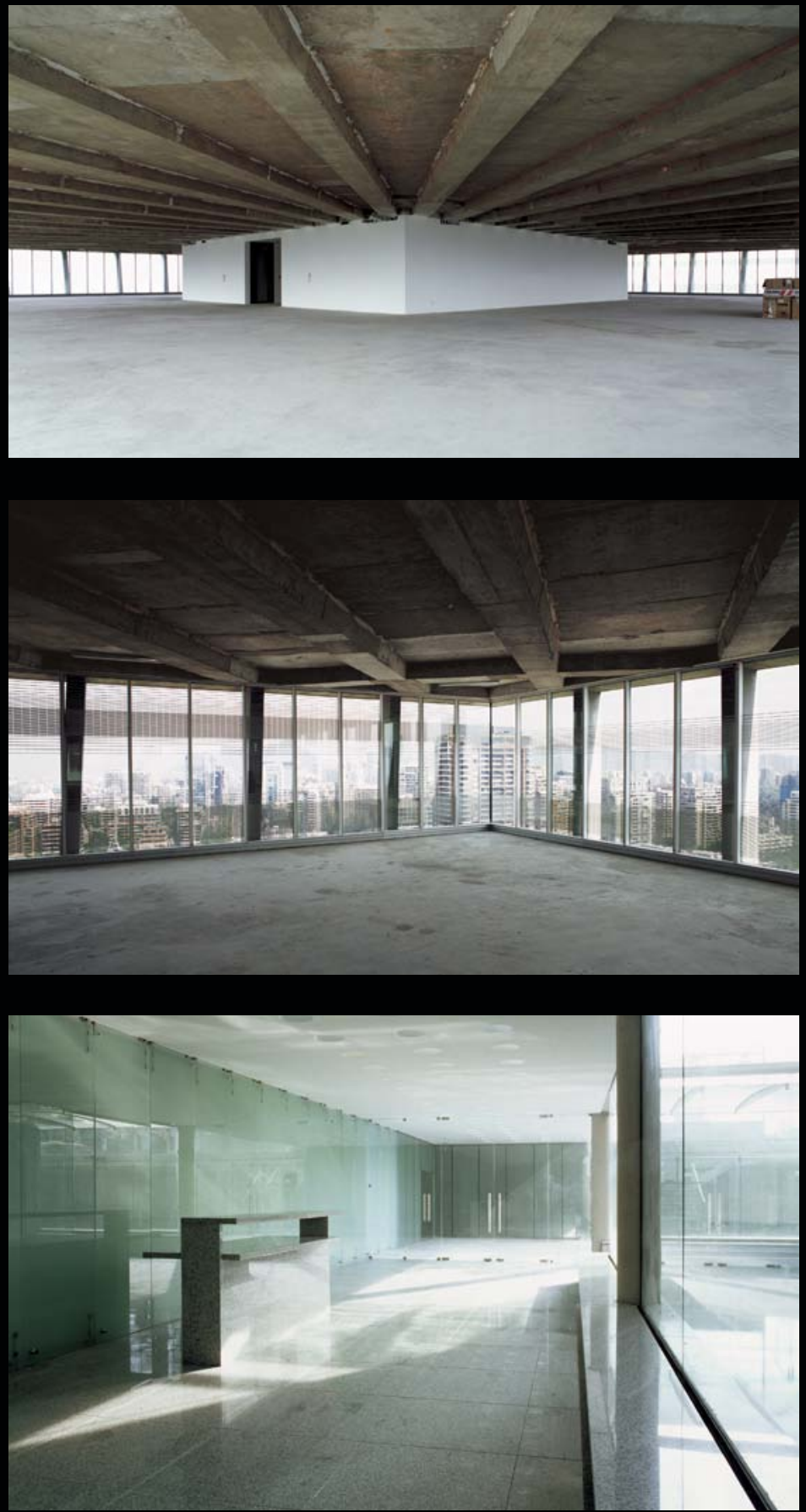

En proyectos previos de torres de pisos de oficinas habíamos visto que lo esencial de este tipo arquitectónico radicaba en el hecho de tener que multiplicar y levantar un suelo, como un loteo servido por una calle vertical, hecho que, primordialmente, se manifiesta como un desafío estructural. En este proyecto esa concepción se radicaliza al entroncarse en el núcleo central la vía vertical de circulaciones y servicios, con la estructura soportante de la torre.

La reducción en la base del volumen - a la altura del cuarto piso- es compensada por la ampliación incremental en los pisos superiores a fin de conservar la superficie total edificada. Esto permite: disminuir el área sombreada por la base suspendida de la torre, mejorando la proporción del espacio exterior cubierto; cerrar el ángulo del apuntalamiento diagonal que descarga la estructura perimetral soportante de la serie de losas superpuestas; aumentar la superficie vendible en pisos altos -cuyo precio es mayor-y definir la silueta de un hito memorable colocado en el remate axial de Avda. Apoquindo.

Por otra parte, al quedar la estructura portante de los pisos resumida al fuste más la serie de columnas del perímetro externo, las plantas quedan libres de pilares interiores. Los ventanales, de piso a cielo, se colocaron en posición vertical retirados $90 \mathrm{~cm}$ respecto del borde de losas, quedando sombreados por un alero continuo y por la trama de pilares, dejando la estructura manifiesta en el exterior del volumen. Esta disposición tragada de las superficies vidriadas, más la especificación de cristales con serigrafías y reflectividades diferenciadas de acuerdo a las necesidades térmicas y lumínicas de cada tramo de fachada, dio como resultado un ahorro en el consumo de energía de aproximadamente un $25 \%$ respecto a edificios de similar categoría de la zona.

El costo de construcción del edificio resultó inferior al estimado inicialmente en relación a edificios de similares características. Decimos esto porque creemos que la economía con que un diseño logra sus cometidos demuestra su ingenio y purifica la retórica arquitectónica; en definitiva, que la eficacia con que se ajustan los medios es condición infalible de la belleza.

Las torres son vistas desde abajo. El triunfo de la estructura sobre la gravedad se hace tanto más perceptible y manifiesto cuanto más nos acercamos a la masa levantada, hasta que ésta como totalidad desaparece de nuestro rango visual y la estimación de las dimensiones cambia con la sensación de peligro, como en el vértigo. La forma trapezoidal de las fachadas y la retícula distorsionada de columnas extraplomadas, que apoyan los cantos perimetrales de las losas, buscan realzar la condición sustancial de la arquitectura en cuanto objeto inmueble, estático: La asimilación mental a un orden ortogonal de esta forma distorsionada induce a un ajuste equívoco de la percepción del aplome y varía según cambia el punto de vista del observador en su aproximación al edificio. En este proyecto hemos querido conjugar sintéticamente la ponderación gravitatoria de la masa con la condición perspectivada del espacio percibido, ambas determinantes de la experiencia arquitectónica. 


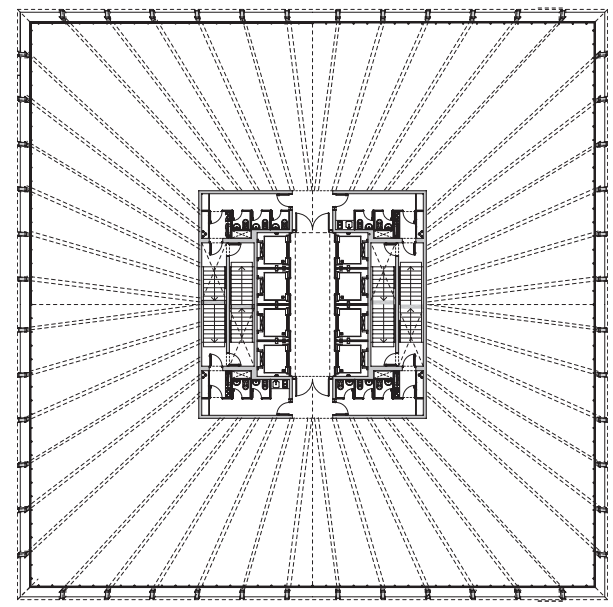

PLANTA $67.21 \mathrm{~m}$
Arquitectos Luis Izquierdo, Antonia Lehmann

Colaborador Juan Hurtado

Ubicación Avenida Apoquindo 4501, Las Condes, Santiago

Cliente Paz Corp

Cálculo estructural Santolaya Ingenierios Consultores

Construcción Echeverría Izquierdo

Instalaciones sanitarias TEFRA

Instalaciónes eléctricas PROPAMAT

Proyecto de iluminación Douglas Leonard Lighting

Climatización Termosistema

Paisajismo Catalina Phillips y María José Labra

Estudio térmico, lumínico y asesoría de fachada Claudio Vásquez

Materialidad estructura de hormigón armado a la vista, estructuras secundarias en acero inoxidable y vidrio estructural, cerramientos de cristal, pavimentos de granito

Presupuesto $12,27 \mathrm{uF} / \mathrm{m}^{2}$ - US\$ 472/ $\mathrm{m}^{2}$

Superficie terreno $3.987 \mathrm{~m}^{2}$

Superficie construida $43.129 \mathrm{~m}^{2}$

Año proyecto 2006 - 2007

Año construcción 2008 - 2009

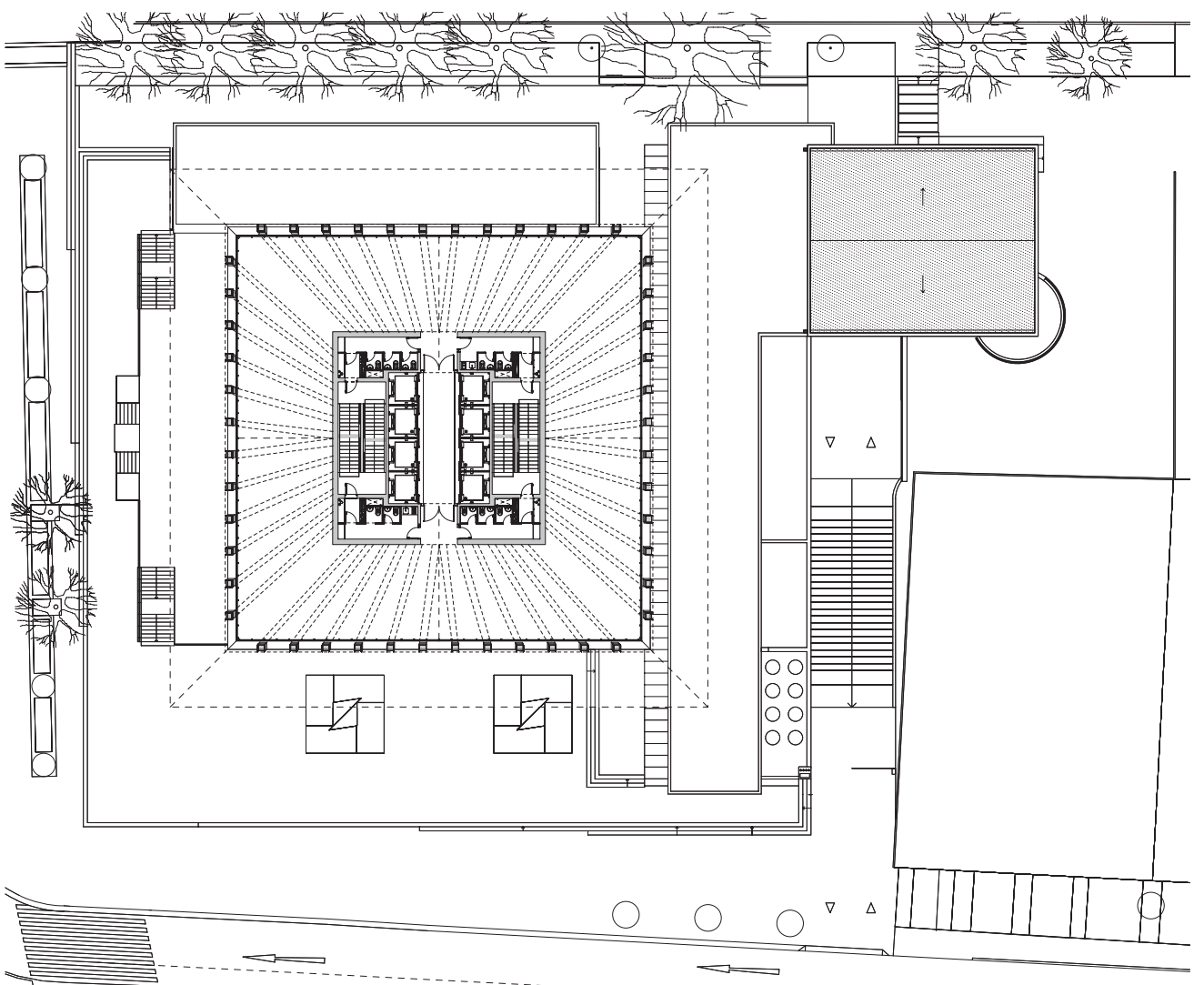

PLANTA $10.26 \mathrm{~m}$ 